\title{
Small pelagic fish, trawling discards and breeding performance of the critically endangered Balearic shearwater: improving conservation diagnosis
}

\author{
Maite Louzao $^{1, *}$, José Manuel Igual ${ }^{1}$, Miguel McMinn' ${ }^{2}$, Juan Salvador Aguilar ${ }^{3}$, \\ Rafel Triay ${ }^{4}$, Daniel Oro ${ }^{1}$ \\ ${ }^{1}$ Institut Mediterrani d'Estudis Avançats IMEDEA (CSIC-UIB), Miquel Marqués 21, 07190 Esporles, Mallorca, Spain \\ ${ }^{2}$ Skua, Gabinete de Estudios Ambientales S.L., Arxiduc Lluis Salvador 5-entl. esq., 07004 Palma, Mallorca, Spain \\ ${ }^{3}$ Laboratori de l'Aigua, Govern Balear, Gabriel Alomar i Villalonga 33, 07006 Palma, Mallorca, Spain \\ ${ }^{4}$ Institut Menorquí d'Estudis, Apartado Correos 32, 07760 Ciutadella, Menorca, Spain
}

\begin{abstract}
Conservation diagnosis should identify which demographic parameters (or vital rates) are having a negative effect on the population growth rate of a threatened organism. Diagnosis can analyse how the environment is influencing the vital rates of this organism. In the present study, we tried to improve the diagnosis of a critically endangered seabird, the Balearic shearwater Puffinus mauretanicus, through analysis of the spatio-temporal variability of breeding performance, using long-term data sets covering most of its breeding range. We also analysed the potential influence of 2 food resources, namely small pelagic fish and trawling discards, as measured by purse-seine and trawling landings, respectively. We found inter-annual variability in breeding performance, which could be related to the changes in the availability of both small pelagic fish and trawling discards. Results showed that these variations affected all study colonies in a similar way, thus supporting previous investigations that identified a major foraging area for the whole breeding population. A fitness landscape suggested that current values of breeding success are not responsible for the sharp decline of the species, although incoming fisheries policies could affect its breeding performance in the long term. Factors affecting adult survival, both at sea and in colonies, remain the most important threat, and conservation efforts should concentrate on these issues to prevent the extinction of this endemic species of the Mediterranean region.
\end{abstract}

KEY WORDS: Balearic shearwater · Conservation diagnosis • Breeding performance · Fitness landscape · Fisheries landing data

\section{INTRODUCTION}

The estimation of demographic parameters is one of the most powerful and reliable tools in diagnosing the level of conservation concern of a species (Krebs 2001). Robustness and reliability of matrix population models in population viability analysis mainly depend on good, unbiased estimators of these demographic parameters (e.g. Saether \& Engen 2002). Conservation diagnosis is directed to identify which demographic parameter is negatively affecting the population growth rate of a threatened organism (Krebs 2001, Norris 2004). Diagnoses are always phrased in terms of differences (or comparisons) in the vital rates in both space and time (Caswell 2001), for instance, by using phylogenetically close and well-known species with similar life histories. Diagnosis also analyses how the environment is influencing the vital rates of a species.

Over the past centuries, changes in the environment caused by human activities have had a negative effect on the functioning of ecosystems and the population dynamics of many organisms (see Botsford et al. 1997). 
This is especially true for species occupying the top level of trophic chains, where environmental changes are amplified.

In marine ecosystems, one of these human activities (i.e. fishery) is responsible for the decline of marine apical species, removing $90 \%$ of large predatory fishes, and is also blamed for an $80 \%$ reduction of the community biomass (Myers \& Worm 2003, Lewison et al. 2004). At the same time, many marine predators with high behavioural plasticity take advantage of fisheries by scavenging on discards and offal (Oro 1999, Tasker et al. 2000). Opportunistic seabirds are good representatives of these organisms, and their populations are showing important changes in numbers resulting from a balance of positive and negative effects due to the birds' interaction with fisheries, such as exploitation of discards and mortality in long lines, respectively (reviewed in Montevecchi 2002; see also Tasker et al. 2000, Lewison et al. 2004).

The critically endangered Balearic shearwater Puffinus mauretanicus, endemic to the Mediterranean region, is an example of a marine top predator specialised in foraging on shoals of small pelagic fishes, which currently interacts in a number of ways with fisheries (Oro \& Ruiz 1997, Arcos \& Oro 2004). A bioenergetics model estimated that $>40 \%$ of the energetic demands of the world population of this species are met by trawling discards (Arcos \& Oro 2002). Oro et al. (2004) estimated an unusually low adult survival rate, which would be unsustainable for such a long-lived organism, and suggested that entanglement in fishing gear could be the main cause of adult mortality. In the latter study, population modelling showed a declining trend for the world breeding population $(\hat{\lambda}=0.926$, $\mathrm{SE}=0.001)$, and mean extinction time was estimated at $40.4 \mathrm{yr}(\mathrm{SE}=0.2)$. In contrast to adult survival, little is known about the potential relevance of other important demographic parameters for the conservation of the Balearic shearwater, such as breeding performance.

Introduced predators such as rats and carnivores, abundant on Mediterranean islands, can negatively affect the breeding performance of shearwaters and other organisms (Martin et al. 2000). On the other hand, incoming fishing policies, aimed at decreasing both fishing efforts (Pauly et al. 2003) and the amounts of discarded fish (Fluharty 2000), are expected to have the opposite effect, with an unknown balance resulting from: (1) a decrease of discard availability and, in turn, an influence on the breeding performance of Balearic shearwaters and (2) an increase in pelagic fish for seabirds following ecosystem restoration.

Taking into account the critical status of Balearic shearwaters, conservation diagnosis can be improved by analysing their breeding performance and the influence of the environment, especially the availability of both small pelagic fish and discards, on this parameter. Here, we were able to compile a long-term historical data set (up to 15 yr) from 6 colonies, covering most of the breeding range of the species. In the case of threatened species, the information available is usually limited to a very small number of colonies and years. However, we decided to use the most consistent time series (i.e. 1997 to 2004) to perform modelling (see Table 1). Our main aims were: (1) to analyse the spatio-temporal variability of breeding performance in Balearic shearwaters, (2) to investigate the influence of fisheries landings as a proxy for food resource availability and (3) to assess the contribution of the breeding success to the population viability of the species.

\section{MATERIALS AND METHODS}

Species details and study area. The Balearic shearwater is a medium-sized Procellariiforme, with an adult body mass of ca. $500 \mathrm{~g}$. The species shares most life-history traits with other members of the family: lays a single egg, has long incubation and chick-rearing stages and large and distant foraging areas. Balearic shearwaters have a small breeding population (ca. 2000 pairs) and are restricted to the Balearic archipelago (Ruiz \& Martí 2004), both situations increasing their conservation concern (Krebs 2001).

The study was conducted from 1986 through 2004 at the 6 main known and accessible colonies. Surveyed colonies (Fig. 1) were of different sizes, ranging from 40 to 300 breeding pairs, and were located in deep caves and between alluvia in coastal cliffs or islets. The introduction of alien species, human harvesting, and coastal development have all contributed to a reduction in the breeding population (Arcos \& Oro 2004, Ruiz \& Martí 2004).

Breeding performance. We visited the colonies at the beginning of the breeding season (mid-March) and marked all accessible nests in order to monitor egg laying. Visits were repeated in mid-May to record the number of hatchlings and in mid-June to count fledglings at each marked nest. Hatching success was defined as the number of chicks hatched (mid-April to early May) divided by the total number of eggs laid at the beginning of the breeding period (late February to early March). Breeding success was calculated as the number of chicks fledged (mid-June to early July) divided by the number of eggs laid.

Fisheries data. The Ebro delta area (one of the main foraging grounds where shearwaters forage during the breeding season; Arcos \& Oro 2002, Ruiz \& Martí 2004) is a favourable spawning area for many fish species 


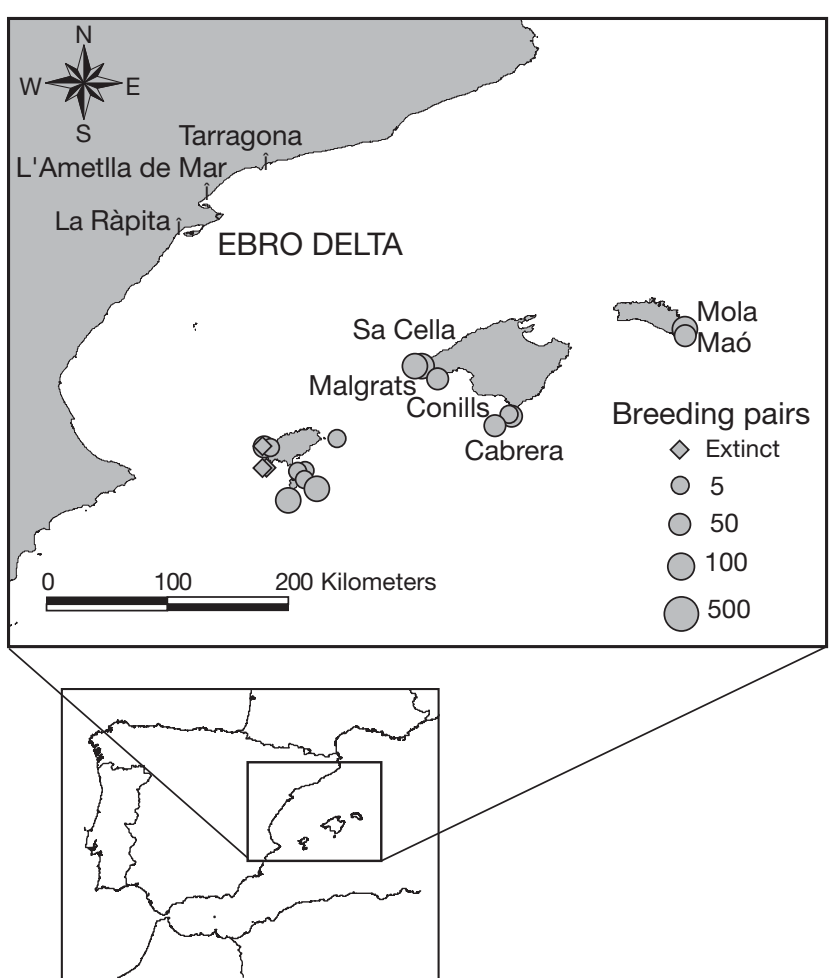

Fig. 1. Puffinus mauretanicus. Map of the study area, showing the Balearic shearwater colonies and their size. Monitored colonies and main fishing harbours mentioned throughout the text are also shown

(Agostini \& Bakun 2002), especially small pelagic fish, and supports one of the largest fishing fleets in the western Mediterranean (e.g. Abad et al. 1998). Catches of anchovy Engraulis encrasicolus in this area are the highest for the Mediterranean (Agostini \& Bakun 2002). The high primary productivity of the area in the Mediterranean context is due to the freshwater input from the Ebro River, the strong winds and a relatively wide continental shelf, coupled with the influence of the Liguro-Porvençal-Catalan front at the continental slope (Salat et al. 2002).

We used statistics of fisheries landings from this area (www.gencat.net/darp/c/pescamar/captures/cestca03.htm) as an index of food resource availability (Montevecchi 2002). In the Ebro delta, there is some evidence that trawling and purse-seine landings are reliable indices of discard availability and small pelagic fish abundance, respectively (Oro 1999, Oro et al. 1999, Lloret et al. 2004). Data on small pelagic fish landings have been used successfully to perform stock biomass assessments and recruitment analyses in the Mediterranean (Santojanni et al. 2003, Lloret et al. 2004). Also, anchovy landings accounted for 38 to $55 \%$ of the biomass estimated by acoustic surveys in the NW Mediterranean in the early 1990s (Abad et al.
1998). Thus, we assumed that small pelagic fish landings could be used as a proxy for their availability for Balearic shearwaters. Concerning trawling discards in the Ebro delta, Oro \& Ruiz (1997) found a positive association between the amounts of fish discarded and landed varying between 15 and $45 \%$. Moreover, Arcos (2001) computed a discard ratio (i.e. relation between discard and landing) representing, on average, slightly more than one-third of total catches (36\%, given the mean discard ratio of $56 \%$ ) in the same area. Also, in the NW Mediterranean, discards of the trawl fleet represent ca. $40 \%$ of the total catch on the continental shelf (Carbonell et al. 1998). All studies were performed in different years and estimated a similar positive relationship between discarded and landed amounts of fish or total catch. Therefore, we assumed that this positive association was consistent throughout the analysed time period. However, trawlers' landing data have to be used with caution, since, in some cases, the relation between discards and catches is not proportional (Rochet \& Trenckel 2005).

These landings were taken from the 3 main fishing harbours which represented ca. $80 \%$ of the total landings in the province of Tarragona (Catalonia, see Fig. 1). L'Ametlla de Mar and Tarragona were taken as representative of the purse-seine catches, and Sant Carles de la Ràpita as representative of trawling catches, since $>90 \%$ of the landings in these harbours corresponded to these types of fishing gear from 2000 through 2004. We analysed the potential association of landings with hatching and breeding success of the shearwaters by grouping the landings by month according to the breeding cycle of the species, with January and February being the pre-laying period, March and April the incubation period and March to June the overall breeding season.

Statistical analysis. We used generalized linear models (GLMs, GENMOD procedure in SAS 2000) (1) to assess the influence of year and colony and their interaction on hatching and breeding success of shearwaters and (2) when testing the relationship between both breeding performance and food resource availability. We considered data from 5 colonies (Cabrera, Conills, Malgrats, Mola Maó and Sa Cella; see Fig.1) collected during the 1997 to 2004 period and excluded previous years because data were too sparse (see Table 1). For these analyses, hatching and breeding success was treated as a binomial dependent variable and fitted using a logit-link function. We evaluated the goodness-of-fit of each model using the Pearson's chi-square statistic (Crawley 1993).

For spatio-temporal analysis of breeding performance, models were compared using Akaike's infor- 
Table 1. Puffinus mauretanicus. Hatching and breeding success of Balearic shearwaters in 6 colonies from 1986 through 2004. Sample sizes (number of nests monitored) are shown in brackets

\begin{tabular}{|c|c|c|c|c|c|c|}
\hline Year & Cabrera & Conillera & Conills & Malgrats & Maó & Sa Cella \\
\hline \multicolumn{7}{|c|}{ Hatching success } \\
\hline 1987 & & & $0.69(16)$ & & & \\
\hline 1993 & $0.44(9)$ & & & & & \\
\hline 1994 & $0.60(5)$ & & & & & \\
\hline 1995 & $0.57(7)$ & & & & & \\
\hline 1997 & $0.56(16)$ & & $0.93(16)$ & & & $0.7(54)$ \\
\hline 1998 & $0.75(16)$ & & $0.81(16)$ & & & $0.50(42)$ \\
\hline 1999 & $1.00(9)$ & $0.71(7)$ & $0.55(20)$ & $0.67(6)$ & $0.78(9)$ & $0.71(24)$ \\
\hline 2000 & $0.80(10)$ & & $0.75(16)$ & $0.93(15)$ & $0.89(19)$ & $0.92(25)$ \\
\hline 2001 & & & $0.56(23)$ & $0.62(21)$ & & $0.68(111)$ \\
\hline 2002 & & & $0.58(26)$ & & $0.90(10)$ & $0.61(94)$ \\
\hline 2003 & & & $0.74(23)$ & & $0.60(15)$ & $0.74(70)$ \\
\hline 2004 & & & $0.52(23)$ & & $0.5(10)$ & $0.56(89)$ \\
\hline \multicolumn{7}{|c|}{ Breeding success } \\
\hline 1986 & & & $0.53(17)$ & 0.7 (17) & & \\
\hline 1987 & & & $0.56(16)$ & $0.33(18)$ & & \\
\hline 1988 & & & $0.67(18)$ & & & \\
\hline 1993 & $0.44(9)$ & & & & & \\
\hline 1994 & $0.6(5)$ & & & & & \\
\hline 1995 & $0.57(7)$ & & & & & \\
\hline 1997 & $0.56(16)$ & & $0.81(16)$ & $1.00(7)$ & & $0.65(54)$ \\
\hline 1998 & $0.69(16)$ & & $0.69(16)$ & & & $0.45(42)$ \\
\hline 1999 & $0.89(9)$ & $0.71(7)$ & $0.45(20)$ & $0.67(6)$ & $0.67(9)$ & $0.68(24)$ \\
\hline 2000 & $0.8(10)$ & & $0.62(16)$ & $0.93(15)$ & $0.84(19)$ & $0.88(25)$ \\
\hline 2001 & & & $0.56(23)$ & $0.62(21)$ & $0.60(10)$ & $0.67(110)$ \\
\hline 2002 & & & $0.58(26)$ & & $0.80(10)$ & $0.53(94)$ \\
\hline 2003 & & & $0.74(23)$ & & $0.60(15)$ & $0.73(70)$ \\
\hline 2004 & & & $0.5(22)$ & & $0.50(10)$ & $0.52(86)$ \\
\hline
\end{tabular}

show how variations of a pair of demographic parameters yield curves with a constant population growth rate $\lambda$ (or population fitness). All parameters of the matrix, except fecundity (i.e. breeding success), were taken from Oro et al. (2004). For our purposes, the landscape was generated using breeding success (the parameter of interest here) and adult survival (the most sensitive parameter for the species). We used mean values (and $95 \%$ confidence intervals) of breeding success estimated at 5 colonies (Cabrera, Conills, Malgrats, Mola Maó and Sa Cella) from which we had at least $5 \mathrm{yr}$ of monitoring data from the historical database (1986 to 2004). Breeding success is a demographic parameter of conservation concern when these distributions are below the curve with $\lambda=1$, i.e. the curve of population stability.

\section{RESULTS}

\section{Breeding performance}

We gathered information on 828 and 840 monitored nests to compute hatching and breeding success, respectively. Sa Cella was a unique colony, free of predators, whereas eradication campaigns have

mation criterion (AIC; see Williams et al. 2001). The model with the lowest AIC is considered the best compromise between model deviance and model complexity, i.e. the number of parameters in the model. When models are within 4 points of AIC, they are considered statistically equivalent (Williams et al. 2001). In this case, we chose the model with fewest parameters, this being the most parsimonious. We tested the effects of year $(t)$, colony $(c)$, additive models $(c+t)$ and their statistical interaction $(t * C)$.

When analysing the influence of food resources, we log-transformed landings data. We hypothesized that (1) both breeding parameters depended on the food availability during the pre-laying period, (2) hatching success depended on nest features (i.e. incubation period) and (3) breeding success was influenced by food availability during the overall breeding season. Significance level was set at 0.05 , and contrast analyses were adjusted by Bonferroni correction.

To assess the contribution of breeding success to the population viability of the species, a fitness landscape was calculated using a deterministic population matrix model (Caswell 2001). The fitness landscape is a tool to been carried out for several years at the other colonies, mostly because of rats. Hatching success values ranged from 0.50 to 1.00 , while breeding success var-

Table 2. Puffinus mauretanicus. Modelling spatio-temporal variability in breeding parameters of the Balearic shearwater in 5 colonies from 1997 through 2004 (AIC: Akaike's information criterion; np: number of estimable parameters in the model). For model notation see 'Materials and methods'. Selected models are in bold

\begin{tabular}{|c|c|c|c|}
\hline Effect & Deviance & $\mathrm{np}$ & $\mathrm{AIC}$ \\
\hline \multicolumn{4}{|c|}{ Hatching success } \\
\hline$t$ & 1016.108 & 8 & 1032.108 \\
\hline C & 1042.417 & 5 & 1052.417 \\
\hline$t+c$ & 1015.528 & 12 & 1039.528 \\
\hline$t+c+t * C$ & 983.806 & 28 & 1039.806 \\
\hline \multicolumn{4}{|c|}{ Breeding success } \\
\hline$t$ & 1070.082 & 8 & 1086.082 \\
\hline C & 1093.236 & 5 & 1103.236 \\
\hline$t+c$ & 1067.641 & 12 & 1091.642 \\
\hline$t+C+t * C$ & 1041.071 & 30 & 1101.071 \\
\hline
\end{tabular}


ied between 0.45 and 0.93 (Table 1). Analysis of the spatio-temporal variability of breeding performance only showed inter-annual variation in the 2 breeding parameters, whereas we did not find any colony effect (Table 2). The goodness-of-fit test indicated that models fitted the data correctly (for hatching success $\chi_{828}^{2}=828.00, p=0.58$; for breeding success $\chi_{832}^{2}=840.00, \mathrm{p}=$ 0.58). Both breeding parameters showed a similar pattern and magnitude during the study period (Fig. 2), suggesting that breeding failure occurs mostly during the incubation and hatching periods and not during the chick-rearing stage.
Table 3. Puffinus mauretanicus. Influence of food resources on breeding performance of Balearic shearwaters. Purse-seine and trawling landings are used as proxies for small pelagic fish and discard availability, respectively. Landings were log-transformed. Significant relationships after applying Bonferroni correction are shown in bold. For breeding cycle explanation see 'Materials and methods'

\begin{tabular}{|llccccc|}
\hline \multirow{2}{*}{ Breeding parameter } & Fisheries & $\chi_{1}^{2}$ & $\mathrm{p}$ & $\chi_{1}^{2}$ & $\mathrm{p}$ \\
\hline \multirow{2}{*}{ Hatching success } & & \multicolumn{2}{c}{ Pre-laying } & \multicolumn{2}{c}{ Incubation } \\
& Purse-seine & 5.26 & 0.022 & $\mathbf{6 . 7 4}$ & $\mathbf{0 . 0 0 9}$ \\
& Trawling & $\mathbf{1 0 . 0 9}$ & $\mathbf{0 . 0 0 1}$ & 3.6 & 0.058 \\
& & & & & \\
Breeding success & & Pre-laying & Breeding \\
& Purse-seine & $\mathbf{7 . 2 6}$ & $\mathbf{0 . 0 0 7}$ & $\mathbf{6 . 0 4}$ & $\mathbf{0 . 0 1 4}$ \\
& Trawling & $\mathbf{1 0 . 7 1}$ & $\mathbf{0 . 0 0 1}$ & 3.94 & 0.047 \\
& & & & & & \\
\hline
\end{tabular}
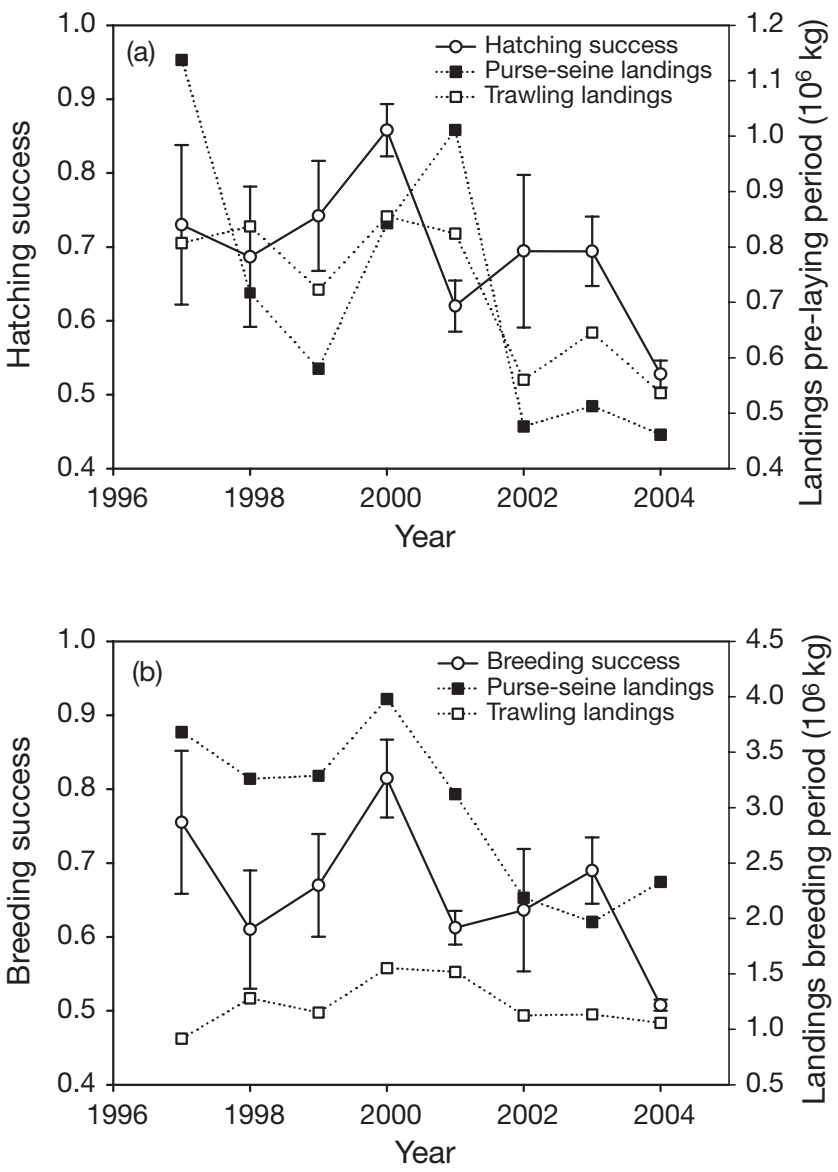

Fig. 2. Puffinus mauretanicus. Inter-annual average of: (a) hatching and (b) breeding success (solid lines) with respect to landings of both fisheries (dashed lines) during pre-laying and breeding period, respectively. Hatching and breeding success were defined as the number of hatchlings and fledglings divided by the total no. of eggs laid, respectively. Note scale difference for both panels on the right axis (landings)

\section{Influence of food resource availability on breeding performance}

Availability of both small pelagic fish and trawling discards during pre-laying positively influenced overall breeding performance (see Table 3). More precisely, breeding success was significantly influenced by the availability of both resources, whereas hatching success was influenced only by discard availability. Both food resources showed a similar trend during pre-laying (see Fig. 2a), and it was not possible to disentangle their influences on hatching success. During incubation, the abundance of small pelagic fish was significantly associated with hatching success (see Table 3). In terms of the whole reproductive season, both small pelagic fish and trawling discards, but particularly the former, influenced breeding success (see Table 3, Fig. 2b). All goodness-of-fit tests indicated that models fitted the data adequately (i.e. all tests were non-significant; results not shown, for clarity).

\section{Fitness landscape}

Once the mean values of breeding success and their confidence intervals on the fitness landscape had been traced (and assuming that 0.9 is the typical adult survival for the species, Fig. 3a), all distributions (each one corresponding to each monitored colony) showed values above the stability line (i.e. the line with $\lambda=1$ ). With such demographic parameters, and considering 0.9 as a very conservative value for adult survival (see Oro et al. 2004), results suggest that with such breeding success, the population would never become extinct. When plotting the esti- 

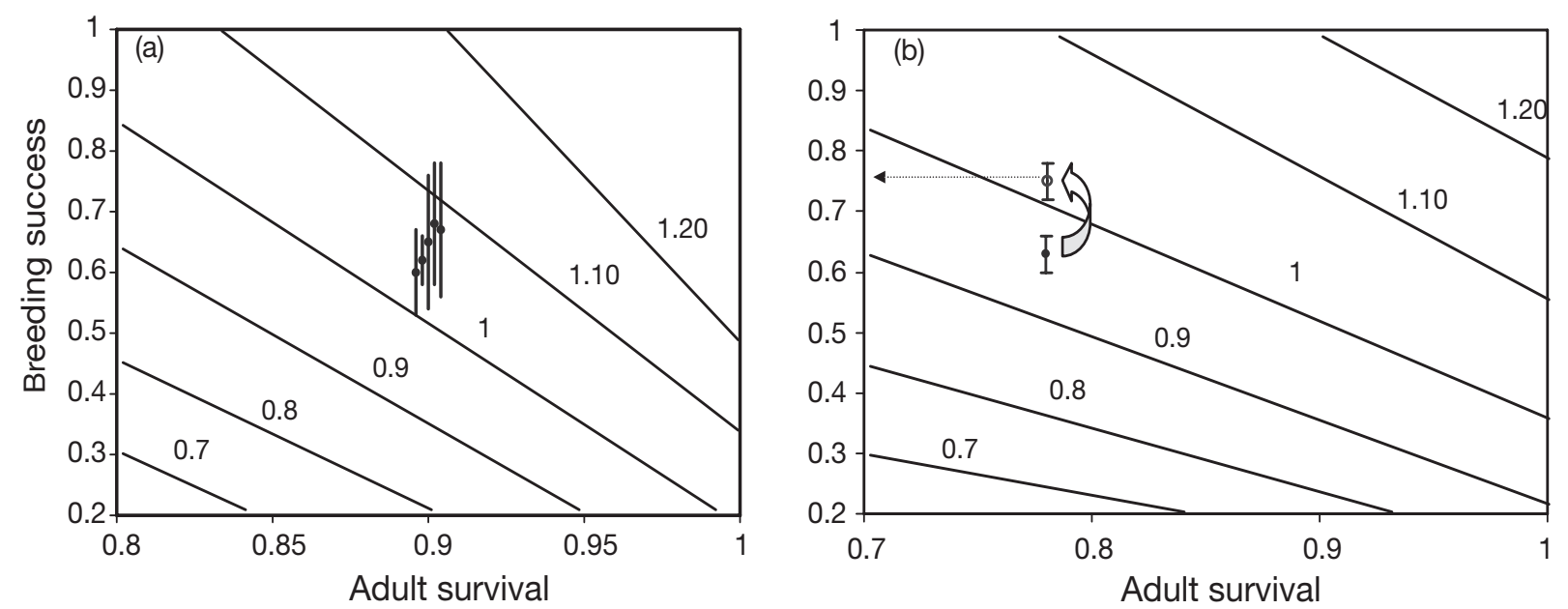

Fig. 3. Puffinus mauretanicus. Fitness landscape of adult survival against breeding success, yielding curves with different values of population growth rate $\lambda(\lambda=1$ represents the curve of population stability). Breeding success was defined as the no. of fledglings per total no. of eggs laid. (a) Mean values of breeding success (together with $95 \%$ confidence intervals) are shown from the 5 study colonies with sufficient data, assuming an adult survival of 0.9 (see Oro et al. 2004). These values have been separated slightly in the figure for the sake of clarity; (b) actual value of estimated survival for the species (0.78 from Oro et al. [2004] shown by the solid dot) is plotted against the mean breeding success of the 5 study colonies (with its $95 \%$ confidence intervals); the arrow points to a hypothetical value of breeding success (shown by the open dot) necessary to exceed the curve of population stability. Error bars are SE

mated actual value of adult survival (0.78), the fitness landscape showed that any conservation measure directed to enhance the breeding success should increase this parameter by ca. $20 \%$ to attain a mean success of 0.75 chicks per pair (Fig. 3b), a value that was reached only in years of high food availability (see Table 1, Fig. 2b).

\section{DISCUSSION}

\section{Spatio-temporal variability in breeding performance and food resources}

Our results show that the breeding performance of Balearic shearwaters Puffinus mauretanicus changed from year to year and that these variations affected all study colonies similarly. Breeding performance of Balearic shearwaters was influenced by the availability of both small pelagic fish (their main prey in natural conditions, i.e. in the absence of trawling fisheries) and trawling discards. The incubation period appears to be the most critical stage with regard to breeding failure; this could be influenced by the prebreeding female condition through temporal variability in food availability (Barbraud \& Chastel 1999). Temporal variability in the breeding performance of shearwaters was probably a reflection of annual changes in the availability of small pelagic fish, which exhibit stochastic temporal patterns. The life history of small pelagic fish (e.g. high mobility, plankton-based food chains and short life span) makes these species particularly sensitive to environmental stochasticity, with quick and dramatic responses to climatic and oceanographic variations (Guisande et al. 2001, Lloret et al. 2004). Our findings suggest that this variability is transported up the food chain, affecting top marine predators such as seabirds (see also Sydeman et al. 2001). Consistently, several studies have demonstrated the influence of climatic oscillations and other oceanographic features (e.g. sea surface temperature anomalies) in the inter-annual variability of the breeding performance of seabirds (Sydeman et al. 2001, Thompson \& Ollason 2001).

In the case of trawling discards, our results support those of Arcos \& Oro (2002), who found that $>40 \%$ of the energetic requirements of Balearic shearwaters during the chick-rearing period are met from the exploitation of trawling discards. Other scavenging seabirds foraging around the Ebro delta area, such as several species of gulls Larus spp. and terns Sterna spp., improve breeding performance when this food resource is available (see Oro 1999 and references therein). This area is an important foraging site, not only for locally breeding seabird populations (such as those settled both in the Ebro delta and off the Columbretes Islands; see Oro \& Ruiz 1997, Oro 1999), but also for those, such as Balearic shearwaters, breeding in distant colonies (see also Abelló \& Oro 1998). 


\section{Contribution of breeding success to the population viability of the Balearic shearwater: improving conservation diagnosis}

We used a fitness landscape to improve the conservation diagnosis carried out by Oro et al. (2004) of the critically endangered Balearic shearwater by focusing on the influence of breeding success on population viability. Other studies on endangered species of vertebrates (e.g. Cuthbert et al. 2002, Todd et al. 2004) have used different tools of population viability analysis to identify and assess threats and to develop practical management options and decisions (e.g. Norris 2004). In our study, the fitness landscape suggested that current values of breeding success in Balearic shearwaters are normal for the species and that factors potentially affecting this parameter (such as food availability) are not of great conservation concern, at least at the present time and in the study colonies. Nevertheless, incoming fisheries policies are directed at reducing the fishing effort and discard rates (Fluharty 2000), with a consequent reduction of food availability (at least in the short term) for scavenging species. This reduction could, in turn, trigger changes in the seabird community and interspecific relationships (Stenhouse \& Montevecchi 1999). For instance, Votier et al. (2004) described how the decrease of discards, particularly when coupled with reduced availability of small pelagic fish, resulted in an increase in predation by the great skua Stercorarius skua on other seabirds in the North Sea. However, future research should focus on using direct estimates of prey availability for seabirds rather than indirect proxies, such as fisheries landings.

Our results also suggested that breeding performance needs to be improved sharply to compensate for the current levels of adult mortality in Balearic shearwaters (Oro et al. 2004). Any conservation measure that sets out to enhance breeding success seems difficult to achieve, owing to the practical constraints involved in altering the levels of food availability for shearwaters. In the Mediterranean, fishery activity and the protection of breeding habitats have been identified as key factors for seabird conservation, but management strategies are difficult to apply because of socio-economic constraints (Mínguez et al. 2003). In the case of the Balearic shearwater, conservation strategies have mainly focused on protecting breeding sites (e.g. campaigns to eradicate introduced predators; Ruiz \& Martí 2004), but the effectiveness of these measures has not been assessed to date. Future research should concentrate on long-term actions and an effective monitoring programme to maintain the protection of breeding sites. Nevertheless, factors affecting adult survival, both at sea and in colonies, remain the most important concern for the conservation of the Balearic shearwater. Efforts should focus on reducing this mortality, which seems to occur mostly during dispersal at sea (Arcos \& Oro 2004, Oro et al. 2004), both in the western Mediterranean and in the North Atlantic.

Acknowledgements. We thank all the people who have helped in the fieldwork over the years, especially those from GOB, GEN, SEO/BirdLife and IMEDEA. We are especially indebted to J. Mayol for pioneering the studies on Balearic shearwaters and for supporting this research over the years. Permits were provided by Conselleria de Medi Ambient (Govern de les Illes Balears), Cabrera National Park and the Military Government of Menorca. Special thanks are due to R. Meliá for the facilities provided during fieldwork. Data on fisheries landings were provided by the Departament d'Agricultura, Ramaderia i Pesca (Generalitat de Catalunya). D. Serrano, M. Genovart and G. Tavecchia provided valuable advice on statistical analyses. Comments by J. M. Arcos and 4 anonymous referees improved earlier drafts of the manuscript. This study was funded by the Cabrera National Park, Govern de les Illes Balears, DISCBIRD and LIFE projects (European Commission) and the Spanish Ministries of Science and Technology (Ref. BOS2003-01960) and of the Environment (Ref. 024A/2002). M.L. was supported by a fellowship of the Conselleria de Innovació, Hisenda i Economia (Govern de les Illes Balears).

\section{LITERATURE CITED}

Abad R, Miquel J, Iglesias M, Alvarez F (1998) Acoustic estimation of abundance and distribution of anchovy in the NW Mediterranean. Sci Mar 62:37-43

Abelló P, Oro D (1998) Offshore distribution and assemblages of breeding seabirds in the Catalano-Balearic Sea (northwestern Mediterranean). Colon Waterbirds 21:422-426

Agostini VN, Bakun A (2002) 'Ocean triads' in the Mediterranean Sea: physical mechanisms potentially structuring reproductive habitat suitability (with example application to European anchovy, Engraulis encrasicolus). Fish Oceanogr 11:129-142

Arcos JM (2001) Foraging ecology of seabirds at sea: significance of commercial fisheries in the NW Mediterranean. $\mathrm{PhD}$ dissertation, University of Barcelona

Arcos JM, Oro D (2002) Significance of fisheries discards for a threatened Mediterranean seabird, the Balearic shearwater Puffinus mauretanicus. Mar Ecol Prog Ser 239:209-220

Arcos JM, Oro D (2004) Pardela Balear, Puffinus mauretanicus. In: Madroño A, González C, Atienza JC (eds) Libro Rojo de las Aves de España. Dirección General para la Biodiversidad-SEO/BirdLife, Madrid, p 46-50

Barbraud C, Chastel O (1999) Early body condition and hatching success in the snow petrel Pagodroma nivea. Polar Biol 21:1-4

Botsford LW, Castilla JC, Peterson CH (1997) The management of fisheries and marine ecosystems. Science 277: 509-515

Carbonell A, Martin P, de Rainieri S, WEDIS team (1998) Discards of the western Mediterranean trawl fleets. Rapp Comm Int Mer Médit 35:392-393

Caswell H (2001) Matrix population models, 2nd edn. Sinauer Press, Sunderland, MA

Crawley MJ (1993) GLIM for ecologists. Blackwell Scientific, Oxford 
Cuthbert R, Fletcher D, Davis LS (2002) A sensitivity analysis of Hutton's shearwater: prioritizing conservation research and management. Biol Conserv 100:163-172

Fluharty D (2000) Habitat protection, ecological issues, and implementation of the Sustainable Fisheries Act. Ecol Appl 10:325-337

Guisande C, Cabanas JM, Vergara RA, Riveiro I (2001) Effect of climate on recruitment success of Atlantic Iberian sardine Sardina pilchardus. Mar Ecol Prog Ser 223:243-250

Krebs CJ (2001) Ecology: the experimental analysis of distribution and abundance. Benjamin Cummings, San Francisco

Lewison RL, Crowder LB, Read AJ, Freeman SA (2004) Understanding impacts of fisheries bycatch on marine megafauna. Trends Ecol Evol 19:598-604

Lloret J, Palomera I, Salat J, Sole I (2004) Impact of freshwater input and wind on landings of anchovy (Engraulis encrasicolus) and sardine (Sardina pilchardus) in shelf waters surrounding the Ebre (Ebro) River delta (north-western Mediterranean). Fish Oceanogr 13:102-110

Martin JL, Thibault JC, Bretagnolle V (2000) Black rats, island characteristics, and colonial nesting birds in the Mediterranean: consequences of an ancient introduction. Conserv Biol 14:1452-1466

Mínguez E, Oro D, De Juana E, Martínez-Abraín A (2003) Mediterranean seabird conservation: What can we do? Sci Mar 67:3-6

Montevecchi WA (2002) Interactions between fisheries and seabirds. In: Schreiber EA, Burger J (eds) Biology of marine birds. CRC Press, Boca Raton, FL, p 27-557

Myers RA, Worm B (2003) Rapid worldwide depletion of predatory fish communities. Nature 423:280-283

Norris K (2004) Managing threatened species: the ecological toolbox, evolutionary theory and declining-population paradigm. J Appl Ecol 41:413-426

Oro D (1999) Trawler discards: A threat or a resource for opportunistic seabirds? In: Adams NJ, Slotow RH (eds) Proceedings of the 22nd International Ornithological Congress, Durban. Birdlife South Africa, Johannesburg, p 717-730

Oro D, Ruiz X (1997) Seabirds and trawler fisheries in the northwestern Mediterranean: differences between the Ebro Delta and the Balearic Islands areas. ICES J Mar Sci 54:695-707

Oro D, Pradel R, Lebreton JD (1999) Food availability and nest predation influence life history traits in Audouin's gull, Larus audouinii. Oecologia 118:438-445

Oro D, Aguilar JS, Igual JM, Louzao M (2004) Modelling demography and extinction risk in the endangered

Editorial responsibility: Howard I. Browman (Associate Editor-in-Chief), Storebø, Norway
Balearic shearwater. Biol Conserv 116:93-102

Pauly D, Alder J, Bennett E, Christensen V, Tyedmers P, Watson R (2003) The future for fisheries. Science 302: $1359-1361$

Rochet MJ, Trenkel VM (2005) Factors for the variability of discards: assumptions and field evidence. Can J Fish Aquat Sci 62:224-235

Ruiz A, Martí R (eds) (2004) La pardela Balear. SEO/BirdlifeConselleria de Medi Ambient del Govern de les Illes Balears, Madrid

Saether BE, Engen S (2002) Including uncertainties in population viability analysis using population prediction intervals. In: Beissinger SR, McCullough DR (eds) Population viability analysis. Chicago University Press, IL, p 191-212

Salat J, Garcia MA, Cruzado A, Palanques A and 7 others (2002) Seasonal changes of water mass structure and shelf-slope exchanges at the Ebro Shelf (NW Mediterranean). Cont Shelf Res 22:327-348

Santojanni A, Arneri E, Barry C, Belardinelli A, Cingolani N, Giannetti G, Kirkwood G (2003) Trends of anchovy (Engraulis encrasicolus, L.) biomass in the northern and central Adriatic Sea. Sci Mar 67:327-340

SAS (2000) SAS/STAT software: user's guide. SAS Institute, Cary, NC

Stenhouse I, Montevecchi WA (1999) Indirect effects of the availability of forage fish and fisheries discards: gull predation on breeding storm-petrels. Mar Ecol Prog Ser 184: 303-307

Sydeman WJ, Hester MM, Thayer JA, Gress F, Martin P, Buffa $\mathrm{J}$ (2001) Climate change, reproductive performance, and diet composition of marine birds in the southern California Current system, 1969-1997. Prog Oceanogr 49:309-329

Tasker ML, Camphuysen CJ, Cooper J, Garthe S, Montevecchi WA, Blaber SJM (2000) The impacts of fishing on marine birds. ICES J Mar Sci 57:531-547

Thompson PM, Ollason JC (2001) Lagged effects of ocean climate change on fulmar population dynamics. Nature 413: $417-420$

Todd CR, Nicol SJ, Koehn JD (2004) Density-dependence uncertainty in population models for the conservation management of trout cod, Maccullochella macquariensis. Ecol Model 171:359-380

Votier SC, Furness RW, Bearhop S, Crane JE and 11 others (2004) Changes in fisheries discard rates and seabird communities. Nature 427:727-730

Williams BK, Conroy MJ, Nichols JD (2001) Analysis and management of animal populations. Academic Press, San Diego, CA

Submitted: June 14, 2005; Accepted: December 8, 2005 Proofs received from author(s): July 10, 2006 